Justine Johnstone

\title{
Towards a creativity research agenda in information ethics
}

\begin{abstract}
:
The value for human wellbeing and social development of information and its associated tools and technologies is no longer controversial. While still less well-endowed than other regions, Africa has growing numbers of print and electronic journals, funding programmes, and researcher and practitioner networks concerned with the generation and use of information in multiple domains. Most of this activity focuses on information as a knowledge resource, providing the factual basis for policy and intervention. By contrast more creative applications of information - as the basis for new ideas whether or not they turn out to be factual - has been almost entirely ignored. Being able to generate and develop new ideas is, however, an equally important and arguably a prior capability, but until recently one that has been little understood. Recent advances in cognitive science and creativity research are changing this, however, and it is now possible to see how a rich research agenda can be developed concerned with the role of information and information and communication technology (ICT) as creative resources.
\end{abstract}

\section{Agenda}

Creativity

Creativity research

Information as a creative resource.....

The theory of conceptual blending

Creative problem-solving blends.....

The role of ICT

Conclusion.....

\section{Author:}

Justine Johnstone:

- $ه$ j.johnstone@sussex.ac.uk 
The value of information and its associated tools and technologies for human wellbeing and social development are no longer controversial. While still less well-endowed than other regions, Africa has growing numbers of print and electronic journals, funding programmes, and researcher and practitioner networks concerned with the generation and use of information in multiple domains. And it now has its own learned society dedicated to studying and promoting the welfare of the African infosphere. This is an exciting time for all those concerned with information and with Africa, and a good moment to consider future research agendas. One area which has so far received almost no attention from either the information or the development community but which is centrally related to human and social wellbeing and which depends fundamentally on information resources is that of creativity. This short paper outlines some directions for a research agenda that it is hoped will become part of the AIES community's work in the future.

\section{Creativity}

The generation of new and valuable ideas is a core component in the ability of individuals and groups both to respond adaptively to change and to envision and bring about change (Runco 2004). As such, creativity is clearly of central importance to human, social and economic development - and yet the concept has received little direct attention in development research, and almost none in informatics and the ICT for development field. The reasons for this are obscure but one might speculate that they could derive in part from the common association of creativity with world-leading achievement in the arts and sciences, and thus apparently a lack of connection with the lives and problems of the poor. In fact this view, while true of some creativity research, represents a small and somewhat outdated conception of the subject, which increasingly focuses on creativity as a universal human capacity and an everyday activity that can be either nurtured or damaged by a wide range of social and environmental factors including information resources and technologies. There is therefore a strong case to be made for a research agenda looking in detail at the linkages between information and creativity in the context of African development.

\section{Creativity as a developmental capability}

Despite the almost total lack of overt reference to creativity in development writing, there are many points of contact at a conceptual level. Creativity research, for example, focuses on a diverse range of phenomena familiar to anyone working in development - for example problem-definition and problemsolving (Mumford et al. 1991), divergent thinking (the ability to come up with multiple possible solutions rather than striving after a single 'right' answer), tolerance of ambiguity, the cognitive flexibility to deal with a changing environment (Flach 1990) and advances in the arts, sciences and technology (Dudek 2003). Creativity has also been studied as an economic driver, through its role in innovation and entrepreneurship (Runco 2004, Stehr 1994) and in the development of the cultural and creative industries.

Similarly concern with aspects of creativity - or its lack - can be found in multiple guises in development literature, including 'cultural dependency' (Seers 1981), project problem-solving (Hirschmann 1967), explanations for changes in models of development (Sikkink 1997), alternative and liberatory ways of thinking (Escobar 1995 ; Shrestha 1995), envisioning a better future as the basis for resistance (Scott 1985) or policy development (Blackmore 1998), innovation and new ideas in participatory practice (Chambers 2005), and the fostering of local research capacity (Kim 1995, Adair 1995).

Development applications of creativity concepts can be roughly categorised as either instrumental or constitutive. In the former case, creativity is valued because of its potential to deliver some other development objective. Hirschmann (1967) for example commented on the role of creative problem solving in development projects and the way in which longterm commitment and irreversibility tended to unleash more creative responses albeit at some cost (Chambers 2005). Similarly, creative arts such as drama and painting can be used to develop awareness and engagement with issues such as gender, HIV or children's rights, or as therapy. ${ }^{1}$ Perhaps the dominant instrumental perspective, however, is an economic one, where creativity is viewed as 'human capital' - a resource with economic value. The creative industries as well as technical and scientific innovation can provide employment, generate revenue, attract investment and broaden the economic base. Even from a purely instrumental point of view then, the importance of fostering creative

${ }^{1}$ It is arguable that therapeutic use of creative expression may be better seen as a constitutive perspective since therapy and self-development are closely allied. 
capabilities is not in question as a development strategy.

A more profound perspective on creativity can, however, be found underlying liberatory and 'people-centred' approaches to development where the ability to free oneself from conceptual constraints, to think differently, to imagine new forms of society and envision a range of alternatives is seen to be not a vehicle for arriving at development but part of the very meaning of development. Such views can be found within, for example, the Marxian concept of 'false consciousness'; Gramsci's notion of ideological control; Freire's 'pedagogy of the oppressed'; liberation theology; dependency theory; the ideational resistance proposed Fanon, Said and Escobar; and also capability theory (e.g. Sen 1999, 1997, 1993, 1992; Nussbaum 2000, 1995; Alkire, 2002).

As well as in the work and meaning of development itself, important but often implicit connections to creativity related concepts can be found in various forms in several policy domains. At an international level, the Universal Declaration of Human Rights asserts rights to freedom of thought, expression, belief - and importantly of the right to change beliefs - and participation in cultural life and the arts and sciences. National policies typically include a central focus on the development of 'human capital' through for example health and education - both of which have deep and complex linkages with aspects of creativity. Cultural and economic policies that aim to promote artistic, technical and scientific development, or industries such as media and tourism, or that focus on innovation and entrepreneurship, also frequently make implicit or explicit reference to the fostering of creativity. Many developing countries, for example, have adopted local content strategies aimed at promoting indigenous media production.

Policy is, however, not just instrumentally related to creativity, but can also be seen as the outcome of creative process, based on a vision of what could be and of how it might be achieved. A number of developing countries have shown high creativity in the development of new policy frameworks and approaches to difficult social problems. For example, South Africa's Truth and Reconciliation Commission shows how a local innovation can come to be globally recognised and influential. The conception of an 'African Renaissance' has similar aspirations and African philosophical concepts such as ubuntu have been creatively used in framing policy and practice in many areas. As recognition grows of the limitations of Western 'domination and exploitation' views of the environment, conceptions of nature drawn from African and other traditions of thought can be expected to enter creatively into policy discussions at a global level.

\section{Creativity research}

Studies of creativity are standardly classified into four main focal categories (Rhodes 1961/1987):

- $\quad$ Person - the traits, abilities, motivational and affective states, and behaviours that appear to be correlated with creativity such as the work of Barron and Harrington (1981) and Amabile (2003).

- $\quad$ Process - the cognitive and social dynamics governing the generation, expression and acceptance or adaptation of new ideas (e.g. Martindale \& Hasenfus 1978, Runco 1991, Csikszentmihalyi 2003).

- Press - pressures in the social and material environment that enhance or inhibit creativity (Murray 1938), such as access to resources, family or organisational structure, support for and valuing of originality, or the need to find solutions to urgent problems (e.g. Amabile \& Gryskiewicz 1989, Will \& Beorkrem 1989, Sulloway 1996, Albert \& Runco 1989, Amabile 2003).

- $\quad$ Product - studies of creative outputs such as publications, patents or art works (Simonton 1984, Gardner 1993).

Runco (2004) further identifies a significant amount of creativity research with a disciplinary focus, some of which cuts across the focal categories or fails to fit the classification scheme. Those of particular relevance to development domains include:

- Connections between physical and mental health and creativity (Maslow 1971, Rogers 1970, Runco \& Charles 1997).

- Cognitive research on memory, attention, knowledge, intuition, imagination, problemfinding and conceptualisation, as well as specific thinking techniques and skills (e.g. Pollert et al. 1969, Martindale \& Greenough 1973, Mumford et al. 1991, Runco 1999).

- Research on family structure (Sulloway 1996) and gender roles and differences (Harrington et al. 1983, Reis 1999) in creativity.

- Economic theories relating creativity to socioeconomic status (Dudek et al. 1993) or to 
conceptions of 'human capital' (Walberg \& Stariha 1992).

- $\quad$ Studies of educational practices such as testing techniques (Reiter-Pelmon et al. 1997), classroom environment (Wallach \& Kogan 1965) and teacher attributes and expectations (Graham et al. 1989, Runco 1992, 1989, 1984).

- Research on creativity in organisations and groups (Amabile 2003, Witt \& Beorkrem 1989, Runco 1995, Rubenson \& Runco 1992) and on innovation (reviewed by Service 2003 and Rickards \& deCock 2003).

- Connections between social processes and creativity (Amabile 2003, Paulus \& Nijstad 2003) and the effectiveness of social techniques such as brainstorming (Rickards \& deCock 2003).

- $\quad$ Studies of creativity domains (Gardner 1983); the addition of new domains such as morality (Stein 1993, Gruber 1993) and nature (Solomon et al. 1999), and the increasing recognition given to 'everyday' creativity as part of normal problem-solving (Cohen \& Ambrose 1999, Runco \& Richards 1997).

- Cultural differences in creativity such as levels of social control (Aviram \& Milgram 1977), attitudes and values (Johnson et al. 2003), expectations (Dudek at al. 1993), domain differences (Runco 2004) and also similarities for example in childhood developmental research (Raina 1984).

Other authors have suggested other classificatory schemes - Hemlin, Allwood and Martin (2004), for example, argue that environmental influences on creativity need to be studied at the micro, meso and macro level. There is thus no simple way of characterising the field but rather - and perhaps appropriately - a broad and divergent body of work cutting across multiple disciplines all with useful if very different contributions to make. As a result an African creativity agenda has the potential to open up an extremely rich and interesting field of investigation.

\section{Information as a creative resource}

Information is the raw material of human thought. Without access to information and the ability to process it effectively we cannot meet our basic survival needs, relate to others, do our jobs or find our way around the world. Whether acquired as sensory input, through social learning or, as nativists believe, partially encoded by evolution, information is the medium in which our minds operate, and the transformation of information - in visual, verbal, spatial, symbolic or another form - is thinking. Some of this thinking is about factual knowledge - working out how clean a water source is or how many children go to school or where there are no jobs but a great deal is about how things could, should or might be, or could, should or might have been. These 'counterfactual' or imaginative thought processes depend on information just as much and are just as important as than those involved in knowledge acquisition ${ }^{2}$ but have received barely a fraction of the attention from academic, practitioner and policy communities.

One reason for the lack of attention to creative processes in information disciplines is that until quite recently we have had few tools for describing and analysing imaginative phenomena. Recently, however, new approaches have emerged in cognitive science and which seem to offer promising ways of thinking about the creative functions of information and even, perhaps, about the creative foundations of ethical thought itself.

\section{The theory of conceptual blending}

Until recently even in cognitive science it tended to be assumed that the imagination was beyond the scope of empirical investigation and that while it might be possible to correlate creativity with a range of personal, social and environmental factors, the actual mechanisms of new idea production themselves were somehow permanently inaccessible to scientific investigation (Evans et al. 2006). Since the 1990s, however, a powerful and flexible theory known as conceptual blending or conceptual integration has been developed within the field of cognitive linguistics, showing imaginative processes to be systematically involved in human thought and identifiable in language through the use of mapping tools and techniques.

Conceptual blending (CB) is a general theory of idea generation as a process in which elements of two or more 'mental spaces' ${ }^{3}$ are 'mapped' onto one an-

${ }^{2}$ They are in fact heavily involved in the generation of knowledge particularly of a theoretical or probabilistic nature.

${ }^{3}$ Dynamically produced conceptual clusters generated 'on-line' during the process of cognition. 
other and merged to form a third space with emergent properties of its own not found in the two contributing spaces (Fauconnier 1997, Fauconnier and Turner 1998). Conceptual blending, it is argued, is a systematic but complex form of processing that, contrary to traditional views of imaginative thinking, exhibits many standard features and that obeys a number optimality constraints (Fauconnier and Turner 1998, Turner 2001). Much of the time it operates as 'background' cognition at a level below that of conscious thought but it can also be intentionally engaged in during deliberately imaginative cognition.

This theory of dismantling and recombination of elements of symbolic structures has some powerful applications. For Turner, it is the basis of language, and even the distinguishing feature of human intelligence including in particular the processes of metaphor, analogy and counterfactual reasoning that lie at the heart of creativity. Counterfactual reasoning, is also a primary tool of human and social science research (Turner 2001). Historical reasoning for example frequently takes the form of retrospective counter-to-reality speculation, such as 'If the Treaty of Versailles after World War I had not been so punitive, the Nazis would never have gained power in Germany'. Policy disciplines by contrast operate in prospective mode, focusing on the potential results of actions as yet unperformed 'Increasing income tax to fund better health care will be acceptable to the electorate only if they see results quickly'.

According to CB theory what is going on is cases of this sort is in fact a type of thought experiment or mental simulation in which elements of a set of ideas about public services, taxation and health care provision are combined with elements from a set of ideas about public attitudes about tax and services. The policy being proposed is the result of this simulation. In this case it is a conditional result, with the element of speedy results being seen as critical in the formation of public attitudes. The success of the policy, it is being suggested, will depend on whether health care reform can be accomplished in a timescale that integrates with that of public attitude formation. In this way CB theory shows how meanings are creatively manipulated in essentially the same ways in a vast range of everyday and expert thinking.

They draw on more stable conceptual structures such as scripts and schemata.

\section{Creative problem-solving blends}

One interesting area of application for blending theory particularly in the context of African development is in local problem-framing and problemsolving. A large amount of research and many failed programmes across the development agenda testify to the need for problems and solutions to be locally framed and locally owned. Research by the author, for example, found AIDS organisations operating in KwaZulu-Natal identifying needs for 'alternative conceptions' and appropriate 'models', 'strategies', 'approaches', 'programmes' and 'how to' understanding in multiple domains. At the same time, it is clear that new models and local innovations are emerging as communities struggle to come to terms with critical problems for which ready-made solutions do not exist.

While local innovations themselves have to some extent been studied, very little is known about the creative processes through problems are framed and solutions developed locally. Blending theory offers a promising suggestion as to how we might start to undertake such investigations. Consider for example this comment by an NGO worker in a rural area, criticising the way in which social science professionals were advising the closure of orphanages in favour of community care - as she saw it without full understanding of local realities:

The people who work down there in the community are saying, 'our people are so poor, nobody is prepared to take somebody else's child'. One woman keeps about 54 AIDS orphans in her home. She is not rich but she says, 'What can I do, they don't have any other place to go?' She is always open and anyone who wants to come and take those children can come. But nobody comes forward. Most people are so poor. They say, 'Everyone wants to feed those kids but I can't even feed myself. How can I look after somebody else's child?'

In this example we can identify two contributing mental spaces, one associated with the problem situation and one with the proposed solution. The blend - a mental simulation in which the advocated solution is imaginatively implemented in the problem situation - is implied rather than made explicit:

Contributing Space 1 (Problem space - perceived real-life situation): There are many orphans in our community but families do not take them in. 
Contributing Space 2 (Solution space - proposed desired outcome and associated intervention): Children do better in families than in orphanages. Orphanages in this community should close.

Blend (Simulation space - projects intervention into real-life situation generating counterfactual scenario): Local families take in children. Families cannot feed themselves. Implied (unspoken) result is that families cannot feed the orphans either, with disastrous results.

The blend does not cohere but terminates in the asking of a rhetorical question ('How can I look after somebody else's child?') with the implied answer 'You can't'. There is no way to integrate the two contributing spaces and the blend disintegrates. The 'solution' offered by outside experts turns out not to be a solution at all, and the thinker is returned to contemplating the problem space. This example might seem somewhat negative, ending as it does in the rejection rather than the generation of a solution. Failed blends, like reductio ad absurdum arguments, do however do some useful cognitive work. The thinker is not in the same position after running the simulation that she was before. While the solution put forward by the experts has been rejected, the problem ends up being the focus of renewed thought, refocused from a question about the best type of care for orphans to a more fundamental question about poverty and survival.

It is not difficult to see how ethical thinking itself could be conceived in similar terms, for example in considering choices between different courses of action we typically simulate various scenarios in our minds - often socially assisted through dialogue with others - in order to see what their effects might be and how we feel about them. It may even be possible to give quite precise definitions of moral emotions based on this theory. Empathy, for example, could perhaps be seen as a complex blend of an already blended space (a hypothetical 'me in someone else's shoes' space composed of elements of my own subjectivity combined with elements of another person's identity) with an action or event space, giving a composite 'what it would be like for someone else if I did this/if this happened' blend. Simulations of this sort would then feed back in to my conceptualisation of the action or event space, leading me perhaps to adjust my views or intentions in the light of my simulated experience of being someone else.

\section{The role of ICT}

Another direction for research in this field is in investigating the linkages between creativity and ICT. To date research on these topics has been conducted almost exclusively in Western contexts where there is, for example, a significant research agenda examining the effects of electronic environments on various forms of creative activity such as idea generation, problem solving, expressive writing and artistic production (e.g. Wertheimer, 1985; Christensen 1988; Christensen and Tennyson 1989; Moore-Hart 1995; Klein et al. 2003; Klein and Dologite 2000; Yang 2003; DeRosa in press; Delfino in press). In addition, software and hardware development have been seen as creative undertakings; digital media are increasingly being integrated into artistic production and performance, leading to new genres; while on a more macro level whole new creative and content industries are emerging at least some of which may have genuine claims to influencing the economic dynamics of creativity. ${ }^{4}$

In trying to establish some order in this field it may be useful to categorise approaches to ICT and creativity according to the nature of the engagement with technology - for example, whether it is concerned with development, implementation, use or automation (Mateos-Garcia 2006). Development here refers to the process of constructing new and useful technologies, applications and products; implementation to finding new ways of applying existing technologies; use to the instrumental application of ICT as a tool or medium for supporting or enhancing creative activity; and automation to attempts in artificial intelligence to replicate creative activity in machines. In addition, research will vary according to level (individual, social, industry sector etc) and according to object of study or disciplinary orientation - for example, whether it is focused on an individual behaviour, social process or creative outcome of a particular sort. Almost no research in any of these fields has been focused on developing regions of the world - cause for concern given the intimate connection that exists between develop-

${ }^{4}$ The use of the word 'creative' in 'creative industries' does not of course imply any necessary connection with ideas that are either new or valuable. In the UK, for example, the Department of Trade and Industry defines creative industries as those which make money from content or from intellectual property, thus including mobile phone ring tones and satellite navigation systems. 
ment and capabilities such as problem-solving and innovation.

\section{Conclusion}

A considerable amount has already been written on the general topic of information and ICT as contributors to development, and particularly on their importance as resources for development knowledge, communication and interaction. There has not so far been any equivalent focus on information as a resource for more creative development functions such as idea generation and problem-definition. A creativity perspective, it is proposed, may well provide useful insights that complement and enrich existing perspectives on the developmental role of information in the African context. Investigating the mechanics of mental blending and simulation, for example, may show how local perspectives can lead to new and more constructive ways of framing problems, and how expert understandings can be more coherently integrated with local realities. Considering ICT as a creative resource may lead to new ways of lead to new ways of conceiving and evaluating the role of Internet projects such as Development Gateway and Eldis, and suggest new forms of technological intervention and engagement.

It is perhaps not obvious that this is an ethics research agenda, However, as hinted above, creativity research holds out the prospect of new ways of understanding ethical thinking. In addition, a focus on information as a creative resource necessarily incorporates a value dimension, since creativity is explicitly about the production of valuable new ideas. Considerations of who creates new ideas, who they are valued by and for what purposes, how they are propagated and to whom, and how they interact or conflict with other values and interests, are thus necessarily central to a creativity analysis. Ideas are born into political and contested space and how they succeed or fail to achieve recognition and influence can depend on a multitude of social, political and economic factors entirely independent of any intrinsic or technical worth. Thus in considering the role of information, access, participation and influence will be key issues to address. ICT has the technical potential to provide tools for both idea generation and also idea propagation and recognition. However, ICT resources are not equally available to all and even when they are mere access to resources does not enable equal use to be made of them and equal benefits derived. In examining the creative dimension of information and ICT, then, it is essential to consider not only the technical aspects but also the full range of factors affecting the ability of individuals and groups to derive creativity benefits from them. A central part of a creativity agenda in information ethics will thus be the analysis and critique of existing systems and regimes as they impact differentially on the creative capabilities of individuals and groups. If blending theorists such as Turner and Fauconnier are right and creativity in the distinctive mark of our humanity then there can be no more important issue in information ethics.

\section{References}

Adair, J. G. (1995) 'The research environment in developing countries: contributions to the national development of the discipline.' International Journal of Psychology 30.

Albert, R. S. and Runco, M. A. (1989) 'Independence and cognitive ability in gifted and exceptionally gifted boys.' Journal of Youth and Adolescence 18.

Alkire, S. (2002) Valuing Freedoms: Sen's Capability Approach and Poverty Reduction. Oxford: Oxford University Press.

Amabile, T. M. (2003) Within you, without you: towards a social psychology of creativity and beyond.

Amabile, T. M. and Gryskiewicz, N. D. (1989) 'The Creative Environment Work Scales.' Creativity Research Journal 2.

Aviram, A. and Milgram, R. M. (1977) 'Dogmatism, locus of control, and creativity in children educated in the Soviet Union, the United States and Israel.' Psychological Reports 40.

Barron, F. and Harrington, D. (1981) 'Creativity, Intelligence and Personality.' Annual Review of Psychology 32.

Blackmore, C. and Ison, R. (1998) 'Boundaries for thinking and action.' Thomas, A., Chataway, J. and Wuyts, M. Eds.) Finding Out Fast: investigative skills for policy and development. London, Thousand Oaks, New Delhi: Sage Publications in association with The Open University.

Chambers, R. (2005) Ideas for Development. London and Sterling, VA: Earthscan.

Christensen, D. L. (1989) 'Educational technology: Integration?' Computers in Human Behavior 5(2): 137-141.

Christensen, D. L. and Tennyson, R. D. (1988) 'The relationship of learning to technology-based enhancements.' Computers in Human Behavior 4(1): 3-11. 
Cohen, L. M. and Ambrose, D. (1999) 'Adaptation and Creativity.' Runco, M. A. and Pritzker, S. R. Eds.) Encyclopedia of Creativity. San Diego CA: Academic.

Csikszentmihalyi, M. (2003) 'The domain of creativity. ' Runco, M. A. and Albert, R. S. Eds.) Creativity Research Handbook Vol 3. Cresskill NJ: Hampton Press.

Delfino, M. and Manca, S. 'The expression of social presence through the use of figurative language in a web-based learning environment.' Computers in Human Behavior In Press, Corrected Proof.

DeRosa, D. M., Smith, C. L. and Hantula, D. A. 'The medium matters: Mining the long-promised merit of group interaction in creative idea generation tasks in a meta-analysis of the electronic group brainstorming literature.' Computers in Human Behavior In Press, Corrected Proof.

Dudek, S. Z. (2003) 'Art and Aesthetics.' Runco, M. A. (Ed. Creativity Research Handbook. Cresskill NJ: Hampton Press.

Dudek, S. Z., Strobel, M. G. and Runco, M. A. (1993) 'Cumulative and proximal influences of the social environment on creative potential.' Journal of Genetic Psychology 154.

Escobar, A. (1995) Encountering development : the making and unmaking of the Third World. Princeton, NJ: Princeton University Press.

Evans, V., Bergen, B. K. and Zinken, J. (2006) 'The cognitive linguistics enterprise: an overview.' The Cognitive Linguistics Reader Edinburgh: Equinox Publishing Company.

Fauconnier, G. (1997) Mappings in Thought and Language Cambridge: Cambridge University Press.

Fauconnier, G. and Turner, M. (1998), Conceptual Integration Networks' Cognitive Science 22(2); 133-187.

Flach, F. (1990) 'Disorders of the pathways involved in creative process.' Creativity Research Journal 3.

Gardner, H. (1983) Frames of Mind. New York: Basic Books.

Gardner, H. (1993) Creative Minds. New York: Basic Books.

Graham, B. C., Sawyers, J. K. and DeBord, K. B. (1989) 'Teachers, creativity, playfulness and the style of interaction with children.' Creativity Research Journal 2.
Gruber, H. E. (1993) 'Creativity in the moral domain: ought implies can implies create.' Creativity Research Journal 6.

Harrington, D., Block, J. and Block, J. H. (1983) 'Predicting creativity in preadolescence from divergent thinking in early childhood.' Journal of Personality and Social Behaviour 45.

Hemlin, S., Allwood, C. M. and Martin, B. (2004) Creative Knowledge Environments. Cheltenham and Northampton MA: Edward Elgar.

Hirschman, A. O. (1967) Development Projects Observed. Washington, D.C.: The Brookings Institution.

IBRD/World Bank. (2005) Global Monitoring Report 2005 Millennium Development Goals: From consensus to momentum. IBRD/World Bank, Washington.

Johnson, D., Runco, M. A. and Raina, M. K. (2003) 'Parents' and teachers' implicit theories of children's creativity: a cross-cultural perspective.' Creativity Research Journal 14.

Kim, U. (1995) 'Psychology, science, and culture.' cross-sulturl analysis of national psychologies.' International Journal of Psychology 30.

Klein, E. E., Clark, C. C. and Herskovitz, P. J. (2003) 'Philosophical dimensions of anonymity in group support systems: Ethical implications of social psychological consequences.' Computers in $\mathrm{Hu}$ man Behavior 19(3): 355-382.

Klein, E. E. and Dologite, D. G. (2000) 'The role of computer support tools and gender composition in innovative information system idea generation by small groups.' Computers in Human Behavior 16(2): 111-139.

Martindale, C. and Greenough, J. (1973) 'The differential effect of increased arousal on creative and intellectual performance.' Journal of Genetic Psychology 123.

Martindale, C. and Hasenfus, N. (1978) 'EEG differences as a function of creativity, stage of the creative process, and effort to be original.' Biological Psychology 6.

Maslow, A. H. (1971) The Farther Reaches of Human Nature. New York: Viking Press.

Mateos-Garcia, J. (2006) Private communication.

Moore-Hart, M. A. (1995) 'The effects of multicultural links on reading and writing performance and cultural awareness of fourth and fifth graders.' Computers in Human Behavior 11(3-4)

Mumford, M. D., Mobley, M. I., Uhlman, C. E., Reiter-Palmon, R. and Doares, L. M. (1991) 
'Process analytic models of creative capacities.' Creativity Research Journal 4.

Murray, H. A. (1938) Explorations in Personality. Oxford: Oxford University Press.

Nussbaum, M. C. (1992) 'Human Functioning and Social Justice: In Defense of Aristotelian Essentialism.' Political Theory 20(2): 202-246.

Nussbaum, M. C. (1995) 'Human Capabilities, Female Human Being.' Nussbaum, M. C. and Glover, J. Eds.) Women, Culture and Development: A Study of Human Capabilities. Oxford: Clarendon Press.

Nussbaum, M. C. (2000) Women and Human Development: The Capabilities Approach. Cambridge: Cambridge University Press.

Paulus, P. P. and Nijstad, B. A. (2003) Group Creativity. Oxford: Oxford University Press.

Pollert, L. H., Feldhusen, J. F., Van Mondfrans, A. P. and Treffinger, D. J. (1969) 'Role of memory in divergent thinking.' Psychological Reports 25.

Raina, M. K. (1984) Social and Cultural Change and Changes in Creative Functioning in Children. New Delhi: National Council for Education and Research Training.

Reis, S. M. (1999) 'Women and Creativity.' Runco, M. A. and Pritzker, S. R. Eds.) Encyclopedia of Creativity. San Diego CA: Academic.

Reiter-Palmon, R., Mumford, M. D., Boes, J. O. and Runco, M. A. (1997) 'Problem construction and creativity: the role of ability, cue consistency, and active processing.' Creativity Research Journal 9.

Rickards, T. and deCock, C. (2003) 'Understanding organizational creativity.' Runco, M. A. (Ed. Creativity Research Handbook vol 2. Cresskill NJ: Hampton Press.

Rogers, C. (1970) 'Toward a theory of creativity.' Vernon, P. E. (Ed. Creativity. New York: Penguin.

Rubenson, D. L. and Runco, M. A. (1992) 'The psychoeconomic approach to creativity.' New Ideas in Psychology 10.

Runco, M. A. (1984) 'Teachers' judgements of creativity and social validation of divergent thinking skills.' Perceptual and Motor Skills 59.

Runco, M. A. (1989) 'Parents' and teachers' ratings of the creativity of children.' Journal of Personality and Social Behaviour 4.

Runco, M. A. (1991) Divergent Thinking. Norwood NJ: Ablex.

Runco, M. A. (1992) Creativity as an educational advantage for disadvantaged students.
Runco, M. A. (1995) 'The creativity and job satisfaction of artists in organizations.' Empirical Studies in the Arts 13.

Runco, M. A. (1999) 'Time for creativity.' Runco, M. A. and Pritzker, S. R. Eds.) Encyclopedia of Creativity. San Diego CA: Academic.

Runco, M. A. (2004) 'Creativity.' Annual Review of Psychology 55(-1): 657-687.

Runco, M. A. and Charles, R. (1997) 'Developmental trends in creativity.' Runco, M. A. (Ed. Creativity Research Handbook. Cresskill NJ: Hampton Press.

Runco, M. A. and Richards, R. Eds.) (1997) Eminent Creativity, Everyday Creativity, and Health. Norwood NJ: Ablex.

Scott, J. C. (1985) Weapons of the Weak: everyday forms of peasant resistance. New Haven and London: Yale University Press.

Seers, D. (1981) 'Development Options.' Seers, D. (Ed. Dependency Theory: a critical reassessment. Pinter.

Sen, A. (1992) Inequality Reexamined. Oxford: Oxford University Press.

Sen, A. (1993) 'Capability and Well-Being.' Nussbaum, M. C. and Sen, A. Eds.) The Quality of Life. Oxford: Clarendon Press.

Sen, A. (1997) On Economic Inequality. Oxford: Clarendon Press.

Sen, A. (1999) Development as Freedom. Oxford: Oxford University Press.

Service, R. (2003) 'Organizational innovativeness: a comprehensive review and models.' Runco, $M$. A. (Ed. Creativity Research Handbook vol 2. Cresskill NJ: Hampton Press.

Shrestha, N. (1995) 'Becoming a Development Category.' Crush, J. (Ed. Power of Development. London: Routledge.

Sikkink, K. (1997) 'Development Ideas in Latin America.' Cooper, F. and Packhard, R. M. Eds.) International development and the social sciences : essays on the history and politics of knowledge. London, Berkeley CA: University of California Press.

Simonton, D. K. (1984) Genius, Creativity, and Leadership. Cambridge MA: Harvard University Press.

Solomon, B., Powell, K. and Gardner, H. (1999) 'Multiple Intelligences.' Runco, M. A. and Pritzker, S. R. Eds.) Encyclopedia of Ceativity. San Diego CA: Academic. 
Stein, M. (1993) 'Moral issues facing intermediaries between creators and the public.' Creativity Research Journal 6.

Sulloway, F. (1996) Born to Rebel. New York: Pantheon.

Turner, M. (2001) Cognitive Dimensions of Social Science: the way we think about politics, economics, law, and society. Oxford: Oxford University Press.

Walberg, H. J. and Stariha, W. E. (1992) 'Productive human capital: learning, creativity, and eminence.' Creativity Research Journal 5.

Wallach, M. A. and Kogan, N. (1965) Modes of Thinking in Young Children. New York: Holt, Rinehart \& Winston.

Wertheimer, M. (1985) 'A Gestalt perspective on computer simulations of cognitive processes.' Computers in Human Behavior 1(1): 19-33.

Witt, L. A. and Beorkrem, M. (1989) 'Climate for creative productivity as a predictor of research usefulness and organizational effectiveness in an $R \& D$ organization.' Creativity Research Journal 2.

Yang, S. C. (2003) 'Computer-mediated history learning: spanning three centuries project.' Computers in Human Behavior 19(3): 299-318. 